\title{
Application of Draft Tube in the Reduction of Backmixing Rate in Oscillatory Flow in a Baffled Column
}

\author{
*Mohd Sobri Takriff and Zuhrina Masyitah \\ Department of Chemical \& Process Engineering, \\ Universiti Kebangsaan Malaysia, \\ 43600 Bangi, Selangor, Malaysia
}

\begin{abstract}
Oscillatory flow in a baffled tube/column is an efficient way to enhance mixing in a straight smooth column. However, liquid oscillation moving back and forth across the baffle causes backmixing which is a disadvantage when plug flow is desired. This paper presents results from a study conducted to reduce the backmixing rate in oscillatory flow in a baffled column with the use of a draft tube. Results of this study showed that backmixing increases with oscillation velocity and decreases with liquid flow rate. The use of a draft tube reduces backmixing. The backmixing reduction is proportional to the ratio of $L / D_{0}$. However, the draft tube can not be extended too long because it disrupts the flow behavior in the column and creates dead zones near the baffle region. The draft tube length is maximized by extending it to both sides of the baffle, provided that the $L / D_{0}$ on each side of the baffle is at 0.67 or less.
\end{abstract}

\section{INTRODUCTION}

Oscillatory flow in baffled columns has been reported in numerous publications as a very promising method to improve mixing in a straight and smooth tube or column (Hewgill, 1993; Mackley, 1987, Mackley, 1991, Ni and Gough, 1997). Oscillatory flow mixing can be achieved if there is a full reverse flow around baffle plates. This may be produced by oscillating either the fluid or baffle plates (Mackley, 1991). Oscillatory flow in a baffled tube can be characterized by the oscillatory Reynolds number, $R e_{o}$, which describes the intensity of oscillation applied to the system,

$$
R e_{o}=\frac{\rho f x_{o} D}{\mu}
$$

The second equation used to characterize oscillatory flow is the Strouhal number, $S_{t}$, where $S_{t}$ represents the ratio of the orifice diameter to the oscillation amplitude.

$$
S_{t}=\frac{D}{4 \pi x_{o}}
$$

Efficient mixing in oscillatory flow in a baffled tube can be achieved when $R_{e}$ is greater than 150 (Roberts, 1991). Brunold et al. (1989) found that baffle spacing of order 1.5 tube diameter and the constriction ratio of about $60 \%$ was optimal to achieve good mixing in oscillatory condition.

The idea of installing baffles in a column is to approximate the behavior of CSTR in series. With sufficient number of CSTR, plug flow system may be obtained. In the baffled column, each 
compartment between two baffles is to behave like a CSTR where the fluid is well mixed. However, the fluid in a compartment is not supposed to mixed with fluids from adjacent compartments just like in CSTR in series. Application of oscillatory flow in a baffled column produces a certain amount of backmixing, in which fluids in adjacent compartments will mixed together. Such behavior deviates from plug flow behavior, thus it is a disadvantage when plug flow is desired. Howes and Mackley (1990) observed that backmixing occurs in oscillatory flow in a baffled column. However, the effects of the operating parameters and the magnitude of backmixing were not quantified. Zuhrina Masyitah (2001) quantified backmixing in oscillatory flow in a baffled tube. She found that backmixing is a strong function of both the oscillation frequency and the amplitude. This study was carried out to investigate the use of a draft tube to reduce backmixing in oscillatory flow in a baffled column.

\section{MATERIALS AND METHODS}

A schematic diagram of the experimental apparatus is shown in Figure 1. The experiments were carried out in a two-stage baffled column. The height of the column was $282 \mathrm{~mm}$ and the diameter was $94 \mathrm{~mm}$. A pneumatically-driven piston mounted at the bottom of the column was used to oscillate the liquid. The range of the experimental variables used in this study is presented in Table 1. Three types of baffle designs were tested in this work. Table 2 gives the description of the baffles used in the experimental work. The schematic diagrams of the baffle designs are shown in Figure 2.

Table 1: Range of experimental variables

\begin{tabular}{ccc}
\hline No & Variable & Range of value \\
\hline 4 & Liquid flow rate & $0.0-1.2 \mathrm{l} / \mathrm{min}$ \\
5 & Liquid viscosity & $0.001-0.01 \mathrm{~kg} / \mathrm{em}$ 's \\
6 & Oscillation frequency & $0.5-1.0 \mathrm{~Hz}$ \\
7 & Oscillation amplitude & $7.5-15 \mathrm{~mm}$
\end{tabular}

(1)Top plate, (2) Water inlet, (3) Perspex column, (4) Sampling ports, (5) Baffle plates, (6) Injection/sampling port, (7) Water outlet, (8) Piston, (9) Piston bar, and (10) Frame

\section{Figure 1. Schematic diagram of the experimental set-up}

At constant oscillation frequency, amplitude and liquid flow rate, $60 \mathrm{~mL}$ of $30 \mathrm{wt} . \% \mathrm{KCl}$ solution was injected into the exit stage of the liquid phase. Samples were taken from each stage at periodic intervals. The $\mathrm{KCl}$ concentration in each sample was determined by using an electrical conductivity apparatus. The Ideal Stage with Backmixing (ISB) model (Xu, 1994, Takriff et. al. 1998) was employed in this investigation to determine the magnitude of backmixing. The ISB model represents backmixing using finite difference, with the assumption that backmixing flow occurs between adjacent stages in addition 


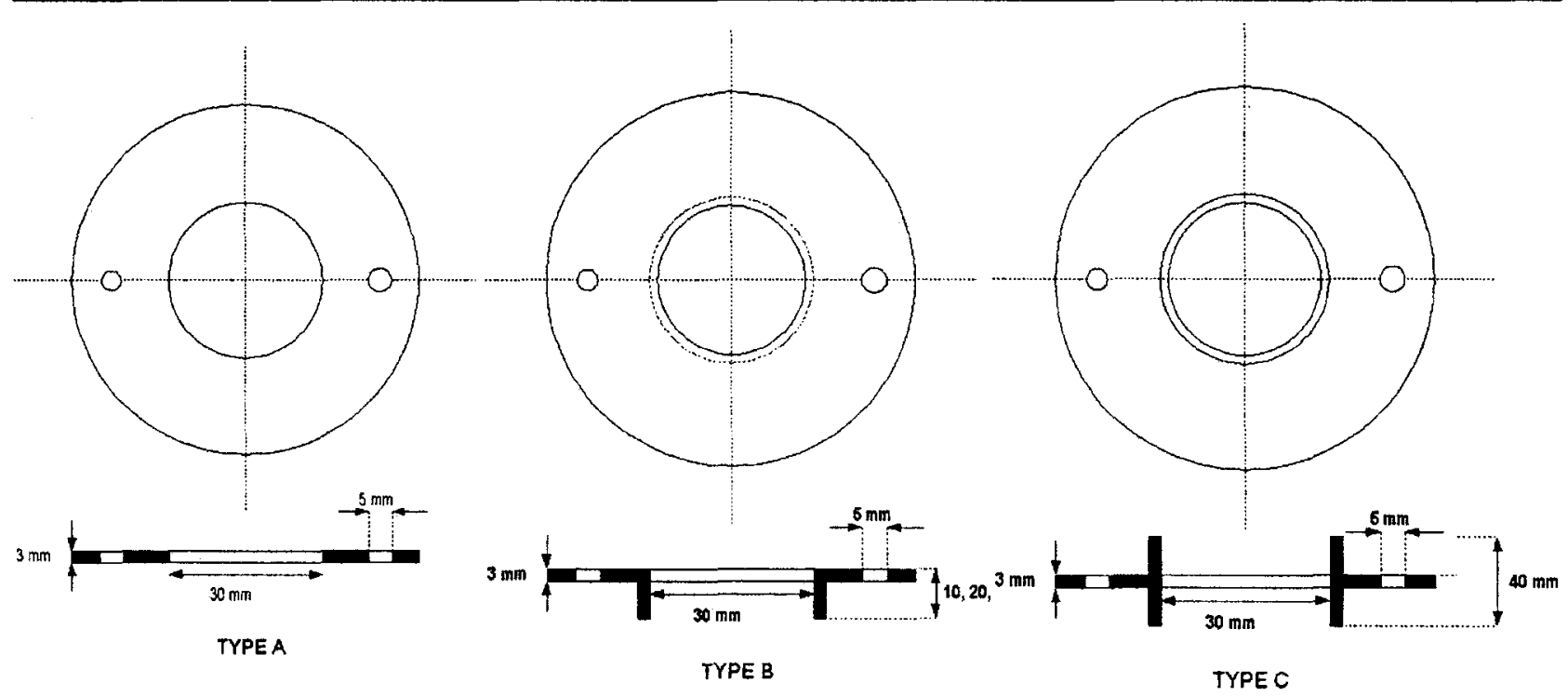

Figure 2. Baffle set-up

to the net forward flow of liquid. For single-phase

flow in the absence of chemical reaction, the mass balance for each component in $j$-stage is given as:

$V_{j}\left(\frac{d C_{j}}{d t}\right)=\left(F_{f}+F_{b}\right) C_{j-1}-\left(F_{f}+F_{b, j}+F_{b, j+1}\right) C_{j}+F_{b, j+1} C_{j+}$

Where $V$ is the stage volume, $F_{f}$ and $F_{i b}$ are forward flow and backmixing flow rates and $C$ is concentration. Application of this equation to each individual stage in the apparatus used for this study gives the following equations. For the first stage:

$$
V_{1} \frac{d C_{1}}{d t}=F_{f, 0} C_{0}+F_{b} C_{2}-\left(F_{f, 1}+F_{b}\right) C_{2}
$$

For the second stage:

$$
V_{2} \frac{d C_{2}}{d t}=\left(F_{f, 1}+F_{b}\right) C_{1}-\left(F_{f, 2}+F_{b}\right) C_{2}
$$

Equations (4) and (5) describe the transient behavior of both stages. Solving these equations for the value of $F_{i b}$ gives the concentrations $C_{1}$ and $C_{2}$ with time. The interstate backmixing rate for a given run was determined by the selection of $F_{b}$, which provided the best match for the experimental result and the predicted transient concentration profiles.

\section{RESULTS AND DISCUSSIONS}

Differential equations (4) and (5) were solved using $\mathrm{Matlab}^{\otimes}$ to obtain the concentration profile for each stage with time. The experimental data were compared with computed values from equations (4) and (5) to determine the backmixing rate. Figure 3 presents a typical match of the experimental concentration profiles and the concentration profiles generated by the ISB model. This figure shows that the ISB model successfully predicted the transient behavior of the column, so it can be used to determine the magnitude of interstate backmixing in oscillatory flow in a baffled column. The average difference between the experimental concentrations and the concentration profiles generated from the ISB model was less than $10 \%$ over the range of the experimental data.

In Figure 4, backmixing velocity is plotted against the oscillation velocity or the product of the oscillation amplitude and the oscillation frequency. This figure shows that backmixing increased linearly with oscillation velocity. As the liquid oscillates back and forth, a certain amount of the liquid back mixes into the previous stage. At a constant frequency, a longer oscillation amplitude displaces the liquid to a further distance and the liquid at the interstate opening are pushed further into the previous stage resulting to higher backmixing rate. While at a constant amplitude, eddies with greater intensity are generated from the interaction of the liquid and the edge of the 


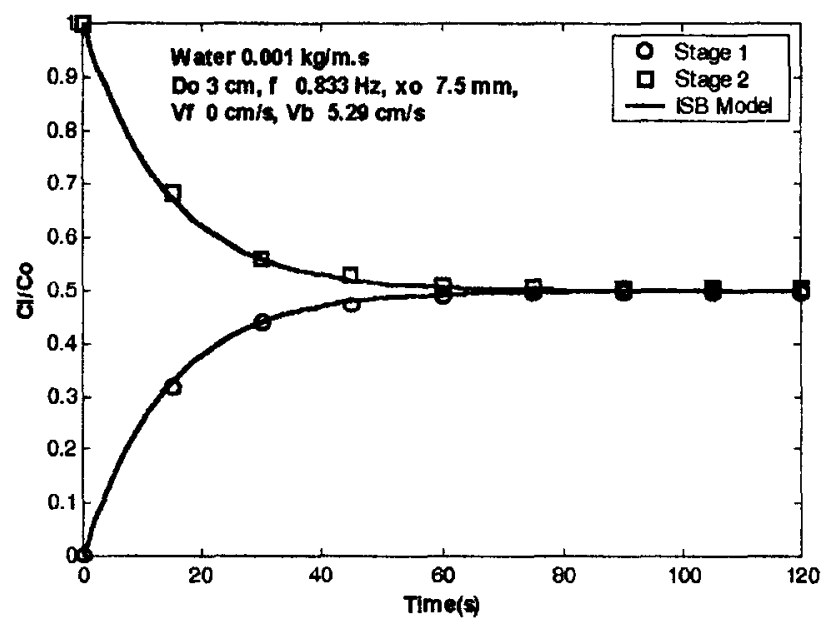

Flgure 3. Experimental data versus data from ISB model

baffle plates, thereby creating a higher value for the oscillation frequency. As a result, a greater amount of liquid at the interstate opening will be pushed into the previous stage and backmixing is increased. Figure 4 suggests that the oscillation amplitude and frequency are dominating variables that influence the rate of backmixing.

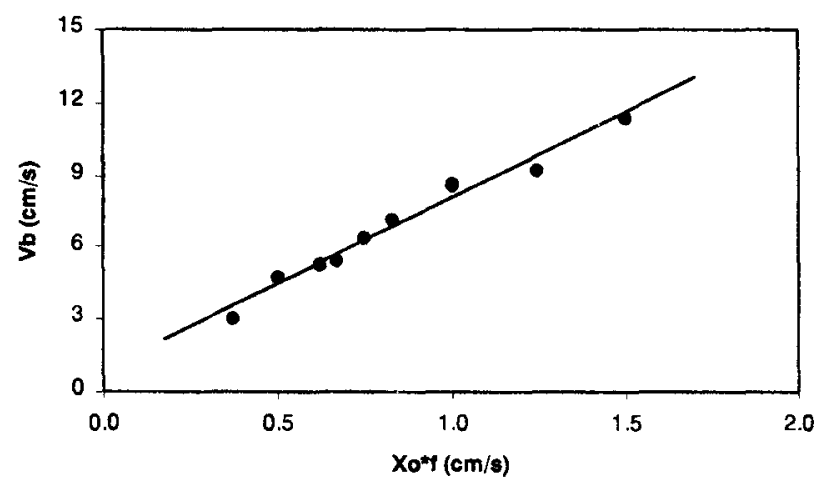

Figure 4. Backmixing velocity versus oscillation velocity

The effects of liquid flow rate on backmixing is presented in Figure 5. This figure shows that maximum backmixing occurs during non-flow conditions. Backmixing gradually decreased linearly when liquid flow rate is increased. A similar observation was made by Xu (1994) and Magelli et. al. (1986) in their backmixing study in an agitated-compartmented column. Forward flow of liquid from one stage to the next, hinders the flow of liquid in the opposite direction or backmix flow. As flow rate increases, the backmix flow encounters a stronger counter direction flows from the forward flow thus resulting to a lower backmixing rate.

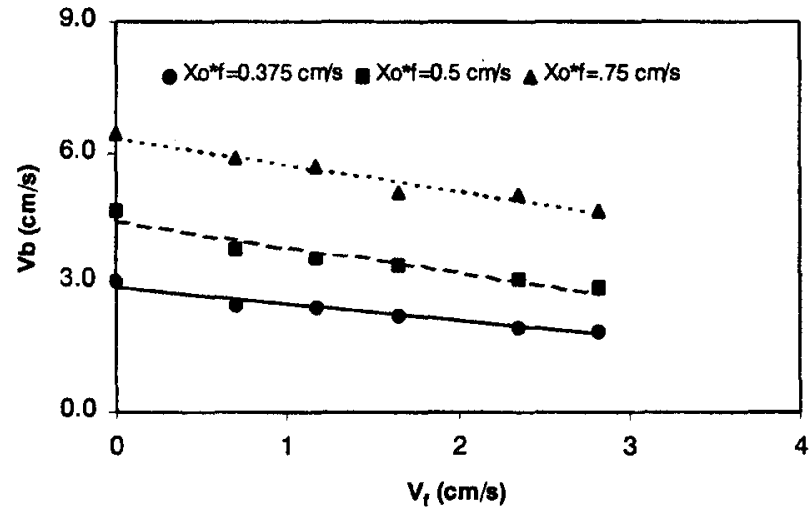

Figure 5. Backmixing reduction with forward liquid velocity

Figure 5 also shows that for a given value of forward velocity, backmixing velocity increases with oscillation velocity. At a constant frequency, a longer oscillation amplitude displace the liquid to a further distance and liquid at the interstage opening are pushed further into the previous stage resulting to a backmixing velocity. While at a constant amplitude, eddies with greater intensity is generated from the interaction of the liquid and the edge of the baffle plates for a higher value of the oscillation frequency. As a result a greater amount of liquid at the interstage opening will be pushed into the previous stage and increases backmixing velocity.

Figure 6 shows the effects of attaching a draft tube to the baffle plate. Three different lengths of draft tubes ranging from 0.0 to 1.33 were investigated. This figure shows that the backmixing rate is reduced with the application of a draft tube. The backmixing rate is reduced by $17 \%$ for $L / D_{0}=0.67$ and $27 \%$ with $L / D_{0}=1.33$. Thus, the reduction of backmixing rate is a function of $L / D$ in which higher values of $L / D$ 。 give lower backmixing rates. A similar observation was made by Vidaurri and Sherk (1985) in their study of a multi-stage agitated mixer. For higher $L / D$ 。 values, fluid has to travel longer distances before they can backmix into the previous stage.

The length of the draft tube however, can not be extended too much because it may disrupt the flow behavior in the column and thus, affect the mixing efficiency. Extending the draft tube too much may create a dead zone near the baffle opening. Such a situation is undesirable as the mixing efficiency in the space between baffles depends on the vortex formation near the baffle 


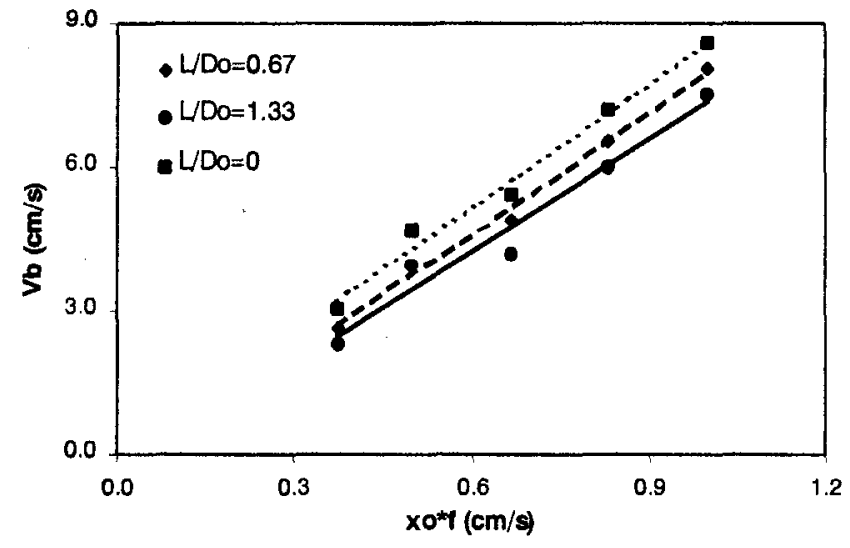

Figure 6. Backmixing reduction with the use type draft tube.

opening. Preliminary CFD simulation study conducted on oscillatory flow in baffled tube shows that the structure of the draft tube has minimal impact on mixing efficiency as long as the $L / D$ is at 0.67 or less. Further study shows that the draft tube may be extended to both sides of the baffle as long as the $L / D$ is not greater than 0.67 on each side. Figure 7 shows the backmixing velocity in the baffle column for two draft tube structures. Type $B$ has a baffle tube at $L / D_{0}=0.67$ and is extended to one side of the baffle, while type $C$ is at $L / D_{0}=0.67$ and is extended to both sides of the baffle. With type $\mathrm{B}$ draft tube, the fluid has to travel at a longer distance before it can backmix into the previous stage. As a result, lower backmixing rate was observed.

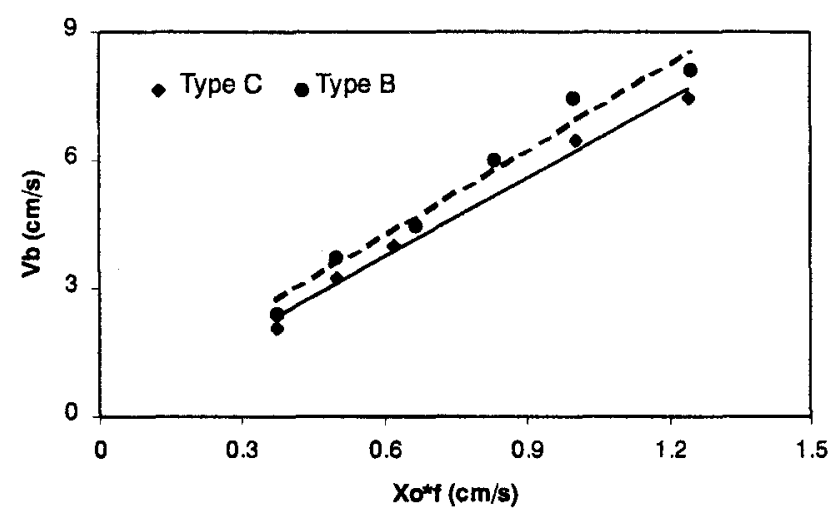

Figure 7. Backmixing with different type of draft tube alignment

\section{CONCLUSION}

Backmixing is significant in oscillatory flow in a baffled column especially at low forward flow

velocity. Backmixing rate increases with oscillation velocity and decreases with liquid flow rate. The use of draft tubes reduces backmixing rate in oscillatory flow in a baffled column. The reduction in backmixing rate is proportional to the $L / D_{\circ}$ ratio. $A$ higher $L / D$ oratio gives lower backmixing rate because the liquid has to travel a longer distance before it backmixes into the previous stage. The value of $L / D_{0}$ however, can not be too high because the draft tube structure may disrupt the flow behavior in the column especially near the baffle opening. Dead zone may be created if the $L / D_{0}$ is too high, thus affecting the mixing efficiency in the space between two baffles. Preliminary CFD simulation conducted in a separate study shows that dead zone form near the baffles on both side of the draft tube for $L / D_{0} \geq 0.67$. Results of this study shows that draft tubes may be used to minimize backmixing as long as the $L / D$ is less than 0.67 . The draft tube length can be optimized by extending it to both sides of the baffle provided that the $L / D_{0}$ on each side is 0.67 or less.

\section{ACKNOWLEDGEMENT}

The authors would like to express their gratitude to the Ministry of Science, Technology and Environment for extending financial support to conduct this study through IRPA Grant: 09 . 02-02-0032.

\section{NOMENCLATURE}

$D$

D。

$f^{\circ}$

$F_{b}$

$F_{f}$

$\mathrm{L}_{b}$

$V_{f}$

$V_{1}$
$V_{2}$
$x_{0}$

$x_{0} f$

$m$

$r$
Column diameter, $\mathrm{mm}$

Opening diameter, $\mathrm{mm}$

Oscillation frequency, $\mathrm{Hz}$

Volumetric backmixing flow rate, $\mathrm{cm}^{3} / \mathrm{s}$

Volumetric forward flow rate, $\mathrm{cm}^{3} / \mathrm{s}$

Length of draft tube, mm

Backmixing velocity through the opening, $\mathrm{cm} / \mathrm{s}$

Forward liquid velocity through stage divider opening, $\mathrm{cm} / \mathrm{s}$

Volume of stage $1, \mathrm{~cm}^{3}$

Volume of stage $2, \mathrm{~cm}^{3}$

Oscillation amplitude (center to peak), $\mathrm{mm}$

Oscillation velocity, $\mathrm{cm} / \mathrm{s}$

Viscosity, $\mathrm{kg} /(\mathrm{m} . \mathrm{s})$

Density, $\mathrm{kg} / \mathrm{m}^{3}$ 


\section{REFERENCES}

Brunold, C.R., Hunn, J.C.B., Mackley, M.R. and Thomson, J.W. "Experimental Observations on Flow Patterns and Energy Losses for Oscillatory Flow in Ducts Containing Sharp Edges". Chem. Eng. Sci., 44, 1989, 12271244.

Hewgill, M.R., Mackley, M.R., Pandit, A.B. \& Pannu, S.S., Enhancement of Gas-Liquid Mass Transfer Using Oscillatory Flow in Baffled Tubes. Chem. Eng. Sci., 48(4), 1993, 799 803.

Howes, T. and Mackley, M.R. Experimental Axial Dispersion for Oscillatory Flow Through a Baffled Tube. Chem. Eng. Sci. 45, 13491358 (1990).

Ingham, J., Slater, M.J. and Retamales, J. "Single Phase Axial Mixing Studies in Pulsed Sieve Plate Liquid-Liquid Extraction Columns". Trans. I ChemE. 72(A), 1995, 492-496.

Mackley, M.R. Using Oscillatory Flow to Improve Performance. The Chem. Eng. February, 1987.

Mackley, M.R. "Process Innovation Using Oscillatory Flow Within Baffled Tubes". Trans. IChemE. 69, 1991, 197-199.

Magelli. F, Fajner. D, and Pasquali, G. "Multistage Mixer Column III". Chem. Eng. Sci. 37, 1986, 141-145.

$\mathrm{Ni}, \mathrm{X}$. and Gough, P. "On The Discussion of Dimensionless Groups Governing Oscillatory Flow in a Baffled Tube". Chem. Eng. Sci. 52, 1997, 3209-3212.

Roberts, E.P.L. "The Simulation of Chaotic Advection for Application to Process Engineering". Trans. IChemE. 69, 1991, 208-210.

Takriff, M.S, Penney, W.R. and Fasano, J.B. "Interstage Backmixing of an Aerated Multistage Mechanically-Agitated, Compartmented Column". The Canadian Journal of Chem. Eng. 76, 1998, 365-369.

$\mathrm{Xu}, \mathrm{B} . \mathrm{C}$., "Interstage Backmixing in Compartmented Agitated Columns: Experimental Determination and Correlation". Ph.D. Dissertation, University of Arkansas, 1994.

Vidaurri, F.C. \& Sherk, F.T. "Low Backmixing in Multistage Agitated Contactors Used as Reactors. AIChE Journal. 31(5), 1985, 705710 .
Zuhrina Masyitah. "Backmixing in Oscillatory Flow in a Baffled Column" MSc Thesis, Universiti Kebangsaan Malaysia, 2001. 


\title{
Sensitivity Analysis of the Life-Cycle Inventories of Electricity and Hydrogen as Energy Vectors for the Philippine Automotive Transport Sector
}

\author{
Raymond R. Tan \\ Chemical Engineering Department, \\ De La Salle University - Manila, Philippines \\ Alvin B. Culaba \\ Mechanical Engineering Department, \\ De La Salle University - Manila, Philippines
}

\begin{abstract}
The Philippine automotive transport sector accounts for a significant portion of the country's petroleum consumption and air emissions. Research in alternative fuels for road vehicles is thus an essential element in the country's long-term environmental management strategy. Two radical vehicle technologies - electrical propulsion systems and fuel hydrogen for fuel cells - are widely considered to be the most promising energy vectors from an environmental standpoint. Electric vehicles (EV) and fuel cell vehicles (FCV) are driven by electric motors; the former use electricity stored in batteries, while the latter generate electricity from the oxidation of hydrogen. Potentially, both electric power and fuel hydrogen can be sustainably produced using renewable energy sources, and their use in vehicles generates almost no direct pollution. However, life-cycle assessment (LCA) may reveal significant environmental impacts from the infrastructure required to produce and distribute these energy vectors on a commercial scale. This study quantifies the life-cycle air emissions and energy balances associated with the use of electricity and hydrogen for motor vehicle propulsion in order to determine which fuel offers more environmental benefits. The assessment uses a modified version of the GREET 1.5a fuel cycle inventory model, with corrections made to account for Philippine conditions. Sensitivity analysis is performed in the model to determine the effect of marginal power generation mix and system transmission losses on the life-cycle inventories of both energy vectors. The results of the simulation indicate that for a given marginal power generation $\mathrm{mix}$, there is no clear-cut advantage in terms of environmental performance for either hydrogen or electricity.
\end{abstract}

Keywords: Life-Cycle Assessment, Alternative Fuels, Sensitivity Analysis

\section{INTRODUCTION}

In the first half of the $20^{\text {th }}$ century the rise in the demand for petroleum-based transportation fuels was partially responsible for stimulating the early development of the chemical engineering profession. It is therefore probable that chemical engineers would likewise play a major role in the commercialization of a new generation of renewable energy vectors or carriers in the near 
future (Lovins, 2000). These developments are driven primarily by environmental concerns, particularly global warming, local air pollution, and energy supply sustainability issues. Hence, future work on the supply infrastructure of these new fuels must concurrently address environmental criteria (Sharatt, 1997). Furthermore, with the emergence of the life-cycle concept, chemical engineers must focus not just on the environmental impacts of the processing plant; the selection and design of environmentally appropriate products and processes should consider the ecological implications of the chain of activities that make up a product life-cycle system (Allen, 1994; Azapagic, 1999).

The transportation sector of any modern economy is both highly energy-intensive and environmentally damaging. In the Philippines, this sector accounted for almost one-fifth of the total primary energy consumption and carbon dioxide emissions in the late 1990s (World Energy Council, 2001; World Resources Institute, 2000).

Concerns about dwindling fossil fuel reserves as well as the greenhouse effect have provided plenty of incentive to develop alternative vehicle propulsion technologies (Philippine Department of Energy, 2000). Electric vehicles (EVs) and fuel cell vehicles (FCVs) are a clean, efficient and promising alternative. Electricity may be tapped from the grid and stored in the EV's batteries. FCVs running on hydrogen gas produced by water electrolysis may also be employed. Although both technologies have yet to become commercially viable, research and development continues at a steady pace (Kaarstad, 1995; Panik, 2000).

While considerable attention has been given to EV's, relatively little research has been done on the viability of the infrastructure needed to support a large fleet of such vehicles (Sharke, 1999). Life-cycle assessment (LCA) is an appropriate method of analyzing the environmental aspects of such energy infrastructure. An excellent description of the LCA concept is given by the ISO 14040 series (International Organization for Standardization, $1997,1998,2000 \mathrm{a}, 2000 \mathrm{~b})$. LCA is often called fuel-cycle analysis when applied to fuels and energy systems. This study presents a partial, well-to-tank or upstream fuel-cycle analysis. This approach is justifiable since EVs and FCVs have comparable fuel economies (Wang, 1999) and generate virtually no tailpipe emissions from direct vehicle operation.

\section{OBJECTIVES}

The objective of this study is to generate a life-cycle inventory assessment of electrical power and fuel hydrogen for use in motor vehicles under Philippine conditions. Sensitivity analysis is performed with a variety of scenarios in order to account for uncertainties in the model inputs (Wenzel et al, 1997; Tan \& Culaba, 2001). The scenarios are then compared and ranked on the basis of their respective environmental benefits.

\section{THE GREET MODEL}

Greenhouse Gases, Regulated Emissions, and Energy Use in Transportion (GREET) is a publicdomain, life-cycle inventory model for simulating a wide range of existing and anticipated energy vectors for automotive transport. The fuel cycles include conservative technologies such as reformulated gasoline as well as radical energy systems like hydrogen for fuel cell vehicles. Developed by the Argonne National Laboratory (ANL) for the United States Department of Energy, GREET is coded in Microsoft Excel ${ }^{R}$ and can be downloaded from the ANL website (www.transportation.anl.gov). GREET breaks down the full fuel cycle into three broad stages:

- Feedstock Extraction Stage - includes environmental impacts of all operations needed to extract and prepare the fuel raw material or feedstock.

- Fuel Production Stage - includes environmental impacts of all operations needed to convert the feedstock into the fuel product, as well as the movement of the fuel from the processing facility to the refueling point.

- Vehicle Operation Stage - includes direct emissions from vehicle use.

The feedstock and fuel stages combined are known as the upstream (well-to-pump) segment of the fuel life cycle. Although GREET by default calculates emissions per vehicle-mile, in upstream 
analysis environmental impacts are normalized per unit of fuel. This basis is appropriate when one energy unit of each alternative

Table 1. GREET Inventory Parameters

\begin{tabular}{|l|l|}
\hline \multicolumn{1}{|c|}{ Category } & \multicolumn{1}{|c|}{ Model Parameters } \\
\hline $\begin{array}{l}\text { Greenhouse } \\
\text { Gases }\end{array}$ & $\mathrm{CO}_{2}, \mathrm{CH}_{4}$ and $\mathrm{N}_{2} \mathrm{O}$ \\
\hline $\begin{array}{l}\text { Regulated } \\
\text { Emissions }\end{array}$ & $\mathrm{VOC}, \mathrm{CO}, \mathrm{NOx}, \mathrm{PM}_{10}$ and SOx \\
\hline Energy Use & $\begin{array}{l}\text { Total, Fossil and Petroleum } \\
\text { Energy }\end{array}$ \\
\hline
\end{tabular}

Source: Wang (1999)

As the name implies, GREET focuses on greenhouse gases, specific air emissions, and energy inputs. Greenhouse gases are of interest due to concerns about global warming. Miscellaneous air emissions contributing to photochemical smog formation, acid rain formation, and direct toxicity effects are also included in the model. Energy demands are assessed by the model as a measure of natural resource depletion impacts. The fossil energy parameter measures the extent to which a fuel cycle is dependent on non-renewable energy sources. The petroleum energy parameter is significant since it quantifies the degree to which an alternative fuel displaces demand for oil.

GREET is a spreadsheet-based input-output model utilizing basic material and energy balance (MEB) principles. A detailed description of its computational structure is given by Wang (1999). Hence, only the salient features of the model are described here. GREET is structured around a "backbone" energy balance model consisting of a chain of energy conversion processes or transportation activities (Hocking, 1999). This chain begins with a raw material which is progressively converted into useful form and eventually delivered to the end-user for vehicle propulsion use. Each stage in the chain typically requires additional process energy for operation. For example, a hydrogen liquefaction process converts a feedstock (gaseous hydrogen) into a finished product (liquid hydrogen). However, the process itself requires the use of electricity and other auxiliary energy inputs which, together with the feedstock consumption, make up the total energy demand.
Process efficiency as used in the GREET model is defined as the ratio of the fuel value of the product to the total energy input into the processing stage:

$$
E=\mathrm{NHV}_{\mathrm{P}}\left(\mathrm{NHV}_{\mathrm{F}}+\mathrm{PE}\right)-1
$$

where:

$\mathrm{E} \quad=$ process energy efficiency

$\mathrm{NHV}_{\mathrm{p}}=$ net energy value of product

$\mathrm{NHV}_{\mathrm{F}}=$ net energy value of feedstock

$\mathrm{PE} \quad=$ process energy requirement

The energy balance model that constitutes the core of GREET is expanded into a full inventory model through the use of emission factors, which predict the amount of pollutant per unit of energy (Nieuwlaar et al., 1996). Energy flows calculated in the model are simply multiplied by these factors to determine the quantities of the different air emissions discharged.

\section{MODELING ASSUMPTIONS}

The three energy vectors simulated in this study are electricity, liquid hydrogen and gaseous (compressed) hydrogen. The general features of each energy system are:

- Electrical Power. Electricity generated using the specified marginal power generation mix is delivered to the end-user at various levels of transmission efficiency for battery recharging. Although no emissions are generated by the vehicles themselves, upstream emissions may result due to the increased demand in electricity.

- Liquid Hydrogen. Electricity generated using the specified marginal power generation mix is delivered to the electrolytic plants at various levels of transmission efficiency. Hydrogen production efficiency in the electrolytic cells also vary due to economies of scale. Hydrogen is then liquefied in large, centralized facilites operating at the specified efficiency levels. It is then transported to the refueling stations in bulk tanks by road or rail.

- Gaseous Hydrogen. Hydrogen produced by electrolysis - as in the liquid hydrogen fuel cycle - is transported by pipeline to 
distribution facilities. It is then compressed in the refueling stations at the specified efficiency levels prior to purchase by the enduser.

In this study, the computational structure of the original GREET $1.5 \mathrm{a}$ model was retained. The software model was used as a "shell" to run simulations using input data appropriate to Philippine conditions. Some of these new data were derived from literature and electronic databases as prescribed in standard LCA methodology (Wenzel et al., 1997; ISO, 1998). Default data from the database embedded in GREET 1.5a were also used where appropriate.

The succeeding sections describe the different input data used in this study.

\section{Marginal Energy Mix}

A fleet of commercialized electric or fuel-cell vehicles will require additional power generation capacity since current projections of the Philippine Department of Energy (2000) do not assume any significant power usage by the automotive transport sector. The composition of the source of excess electric power demand is called the marginal energy mix. This additional demand can be met by new power plants; the technology employed in these additional facilities will play a decisive role in determining the environmental benefits of electricity and hydrogen use in road vehicles. In this study three different marginal power scenarios, described in Table 2 , are simulated.

Table 2. Marginal Energy Mix Scenarios

\begin{tabular}{|c|l|}
\hline Scenario & \multicolumn{1}{|c|}{ Description } \\
\hline A & $\begin{array}{l}\text { Marginal energy demand is } \\
\text { generated using non-fossil } \\
\text { (solar, wind, hydroelectric) } \\
\text { energy }\end{array}$ \\
\hline B & $\begin{array}{l}\text { Marginal energy mix is the } \\
\text { same as baseline grid power } \\
\text { mix }\end{array}$ \\
\hline C & $\begin{array}{l}\text { Marginal energy demand is } \\
\text { generated using natural gas }\end{array}$ \\
\hline
\end{tabular}

Scenario A assumes that electricity demands of the transportation sector can be supplied using renewable energy. Hence, for both hydrogen and electricity the air emissions in this scenario are anticipated to be minimal.

Scenario B uses Philippine power mix data from the late 1990s (taken from the electronic database of the World Energy Council). Table 3 presents the share of different energy sources in this scenario.

Table 3. 1996 Philippine Power Generation Mix

\begin{tabular}{|l|c|}
\hline Oil & $49.7 \%$ \\
\hline Coal & $13.3 \%$ \\
\hline Hydroelectric & $19.3 \%$ \\
\hline Others & $17.7 \%$ \\
\hline Total & $100 \%$ \\
\hline
\end{tabular}

Source: World Energy Council (2001)

Scenario $C$ assumes that natural gas is utilized to generate power for electricity production. This case is of particular interest because it represents a pathway by which natural gas can be utilized for transportation. Table 4 presents the composition of Camago-Malampaya natural gas. This gas composition was used in the simulations.

Table 4 Composition of Camago-Malampaya Natural Gas

\begin{tabular}{|l|c|}
\hline \multicolumn{1}{|c|}{ Component } & Percentage \\
\hline Methane & 90.52 \\
\hline Ethane & 2.77 \\
\hline Other Hydrocarbons & 2.20 \\
\hline Carbon Dioxide & 3.77 \\
\hline Nitrogen & 0.74 \\
\hline Sulfur Compounds & 0 \\
\hline
\end{tabular}

Source: Philippine Department of Energy (2000)

\section{Transmission Losses}

The default value for electrical power loss during transmission in the GREET model is $8 \%$. The range of values used in this study is $6-10 \%$, based on the typical coefficient of variation for electrical power suggested by Wenzel et al. (1997).

\section{Process Efficiency}

The process efficiency values used here are based on a recent study by General Motors 
Corporation (2001). The efficiencies, as defined using Equation 1, are given in Table 5.

Table 5. Efficiency Ranges of Hydrogen Production Processes

\begin{tabular}{|l|c|c|}
\hline \multicolumn{1}{|c|}{ Process } & Maximum & Minimum \\
\hline $\begin{array}{l}\text { Water } \\
\text { Electrolysis }\end{array}$ & $80 \%$ & $60 \%$ \\
\hline $\begin{array}{l}\text { Hydrogen } \\
\text { Compresion }\end{array}$ & $96 \%$ & $94 \%$ \\
\hline $\begin{array}{l}\text { Hydrogen } \\
\text { Liquefaction }\end{array}$ & $77 \%$ & $65 \%$ \\
\hline
\end{tabular}

\section{RESULTS AND DISCUSSION}

The life-cycle fossil energy, and petroleum energy requirements of electricity, liquid hydrogen and gaseous hydrogen are shown in Figures 1 3 . If the marginal power generation mix consists exclusively of renewable sources such as wind or solar energy (Figure 1), fossil and petroleum inputs for fuel production are virtually zero for both electricity and gaseous hydrogen. This is not the case for liquid hydrogen, which is transported by bulk using mixed modes of land transport, and the latter are assumed to use petroleum-based fuels. If the marginal power mix is identical to the average grid power mix (Figure 2 ), or is based exclusively on natural gas (Figure 3 ), the energy demands of the EV option are the lowest, while those of liquid hydrogen are highest.

Greenhouse gas (Figures 4-6) and miscellaneous air emissions (Figures 7-9) are directly correlated to fossil energy demands and

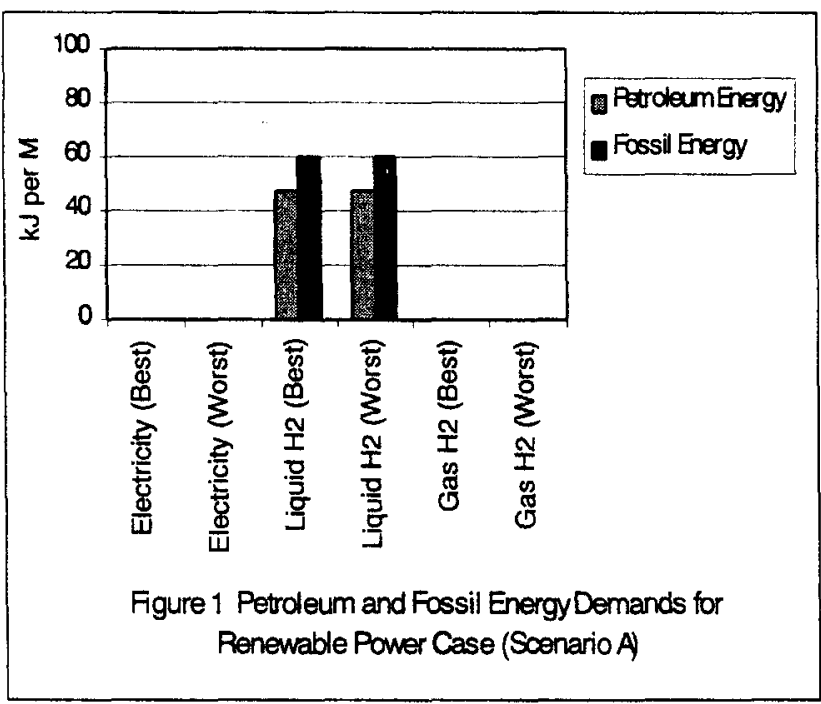

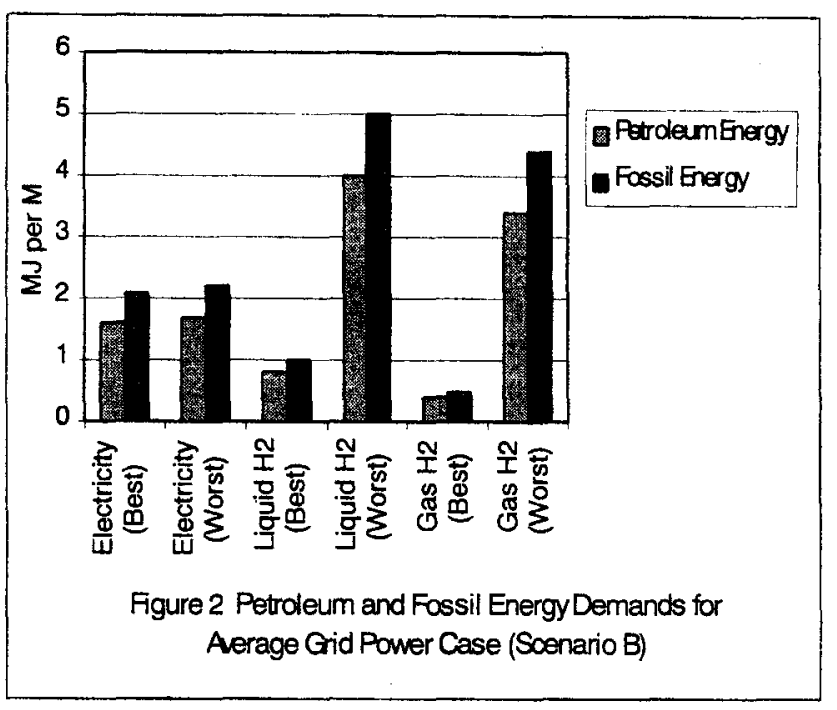
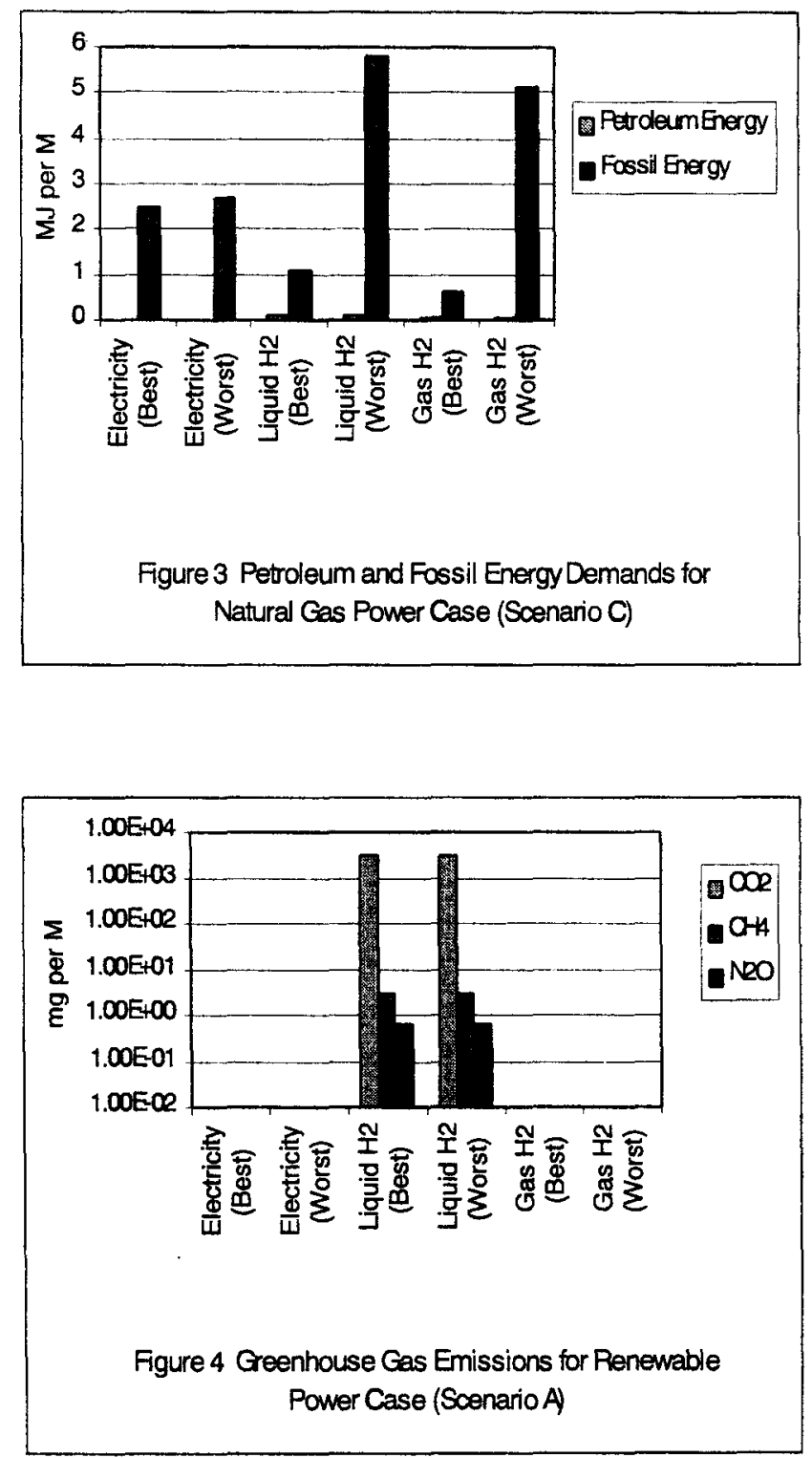

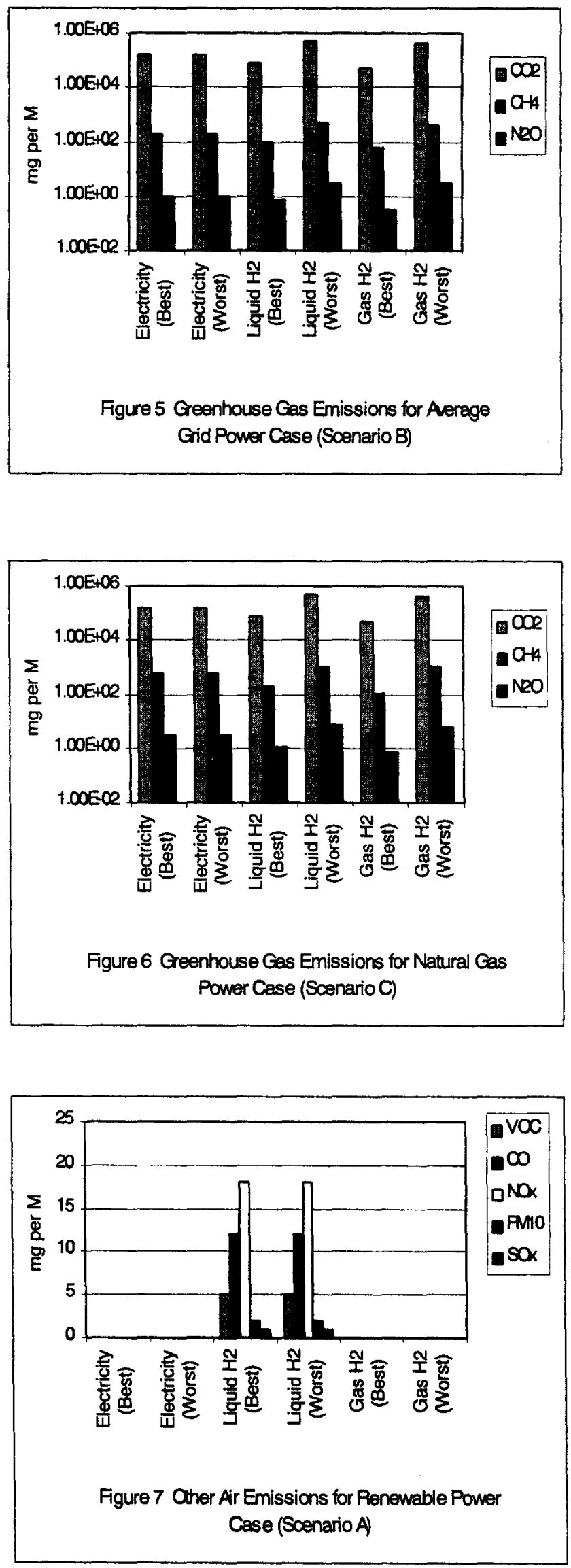

thus follow the same general trend. Greenhouse gas and other air emissions for Power Mix A are shown in Figures 4 and 7, respectively. In this scenario, the electricity and gaseous hydrogen systems generate virtually no pollutants. Some emissions occur in the liquid hydrogen system because bulk distribution of the cryogenic liquid requires the use of petroleum-fuelled vehicles. However, the magnitude of pollutant discharge is actually very minimal and practically negligible.

Comparison of the greenhouse gas and air emissions of Power Scenarios $B$ and $C$ reveal some significant differences. Figures 5 and 6 show that, while the carbon dioxide emissions of the two scenarios are roughly equivalent, methane and nitrous oxides of the natural gas-based scenario
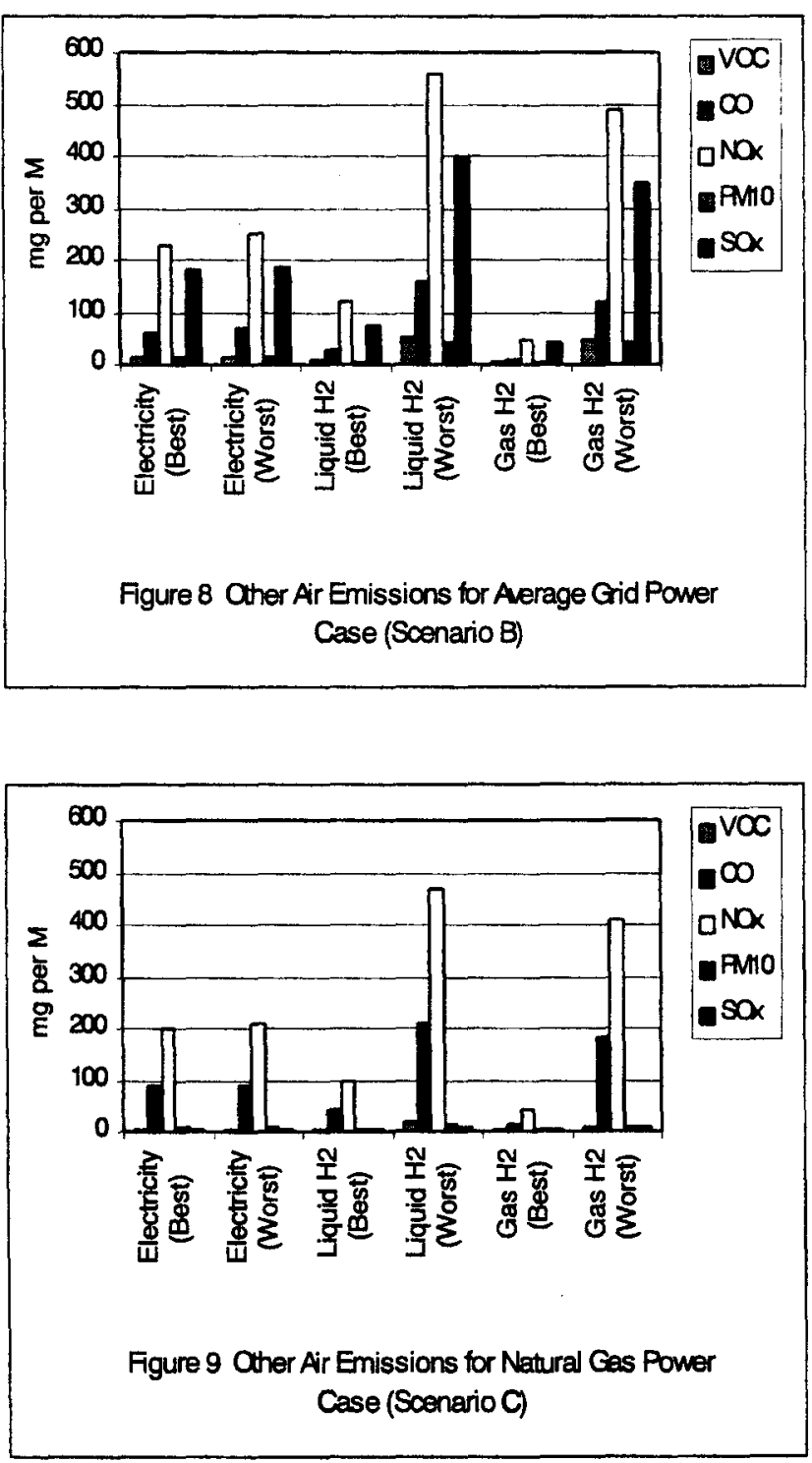
are roughly double those of the mixed-power case. This result implies greater global warming impact when the marginal power demand is met using natural gas-fired power plants. Such an outcome might seem surprising since natural gas is generally considered a very clean fuel. However, it must be noted that, based on Table 3, more than one-third of the Philippine grid power mix is derived from renewable sources such as hydroelectric and geothermal energy.

Analysis of Figures 8 and 9, on the other hand, indicate significant reductions in sulfur and nitrogen oxide emissions when natural gas-based power is used instead of proportionate expansion of the exisiting energy mix. For both hydrogen and direct electrical power, $\mathrm{NO}_{\mathrm{x}}$ emissions are cut by roughly $15 \%$, while $\mathrm{SO}_{\mathrm{x}}$ levels are reduced by one order of magnitude. The latter result can be attributed to the sulfur-free natural gas available in the Philippines.

The superiority of direct electricity utilization stems primarily from energy losses that result from introducing an additional intermediate stage into the fuel cycle - the conversion of electric power into fuel hydrogen by electrolysis. However, the $\mathrm{m}$ anner in $\mathrm{w}$ hich coproduct allocation (Wenzel et al., 1997) is applied in the electrolysis stage has a considerable influence on the relative environmental impacts of these energy vectors.

Roughly $8 \mathrm{~kg}$ of oxygen are generated as a coproduct for every $1 \mathrm{~kg}$ of fuel hydrogen produced. If energy inputs into the electrolytic process are allocated on a mass basis between the two products, there will be dramatic reductions in both energy demands and air emissions associated with the fuel hydrogen. In effect, since energy is allocated in proportion to the masses of the coproducts, only $1 / 9^{\text {th }}$ of the energy demand of electrolysis will be considered as being utilized for the production of hydrogen; the balance is considered as the input required for generating the oxygen coproduct.

The same argument applies for the air emissions associated with these energy flows. Such an allocation scheme is realistic if the oxygen coproduct is to be fully recovered and subsequently processed into an economic commodity. However, if the volume of hydrogen production is such that the amount of oxygen available outstrips the commercial demand, any excess oxygen would have to be vented into the atmosphere and the coproduct allocation would no longer be appropriate.

\section{CONCLUSIONS}

Life-cycle assessment is a tool for simulating and modeling the cumulative environmental effects of complex industrial systems. As research in the field of alternative automotive fuels continues, this methodology is anticipated to become particularly useful to chemical engineers who must incorporate environmental decision criteria in designing optimal process systems (Sharrat, 1997). Selection of an optimal alternative using life cycle modeling often involves tradeoffs between advantages and disadvantages, thus necessitating some form of multi-criterion analysis technique (Azapagic, 1999). In this study, a high degree of correlation was observed among the different air emissions and energy demands, thus allowing conclusions to be drawn with minimal conflict with respect to the different environmental criteria used.

Evaluation of different system efficiency and power generation mix scenarios reveal that electricity is generally superior to fuel hydrogen with respect to both energy input and air emission profiles. This is due primarily to the additional system inefficiency that results when electrical power is converted by electrolysis into hydrogen, as opposed to simply being utilized directly to recharge $\mathrm{EV}$ batteries. Coproduct allocation in the hydrogen production (electrolysis) stage was found to have significant implications on over-all environmental performance. If oxygen is assumed to be a commercially valuable coproduct, the environmental impacts of both the gaseous and liquid hydrogen fuel cycles are drastically reduced. On the other hand, if the oxygen is merely vented into the atmosphere as waste product, all energy inputs for electrolysis (along with the associated emissions) are allocated to the fuel hydrogen. These two extremes represent the best- and worstcase impact scenarios of the hydrogen fuel cycle.

Further comparison between liquid and compressed hydrogen shows that the latter is marginally superior, because compression of hydrogen requires considerably less energy than cryogenic liquefaction. Furthermore, the bulk distribution of liquid hydrogen generates more emissions per unit energy than pumping gaseous 
hydrogen through a transmission pipeline. A more comprehensive analysis of these alternative energy vectors would probably be necessary in order to account for emissions of liquid and solid wastes from the fuel life cycles; the status of vehicle technology will obviously also be a pivotal factor in determining commercial feasibility.

\section{NOMENCLATURE}

\begin{tabular}{|c|c|}
\hline EV & Electric vehicle \\
\hline FCV & Fuel cell vehicle \\
\hline GREET & $\begin{array}{l}\text { Greenhouse Gas, Regulated } \\
\text { Emissions and Energy Use in } \\
\text { Transportation }\end{array}$ \\
\hline LCA & Life cycle assessment \\
\hline NG & Natural gas \\
\hline VOC & Volatile organic compounds \\
\hline $\mathrm{PM}_{10}$ & $\begin{array}{l}\text { Particulate matter of size less than } \\
10 \text { microns }\end{array}$ \\
\hline
\end{tabular}

\section{MATHEMATICAL NOTATION}

$\mathrm{E}=$ process energy efficiency

$\mathrm{NHV}_{\mathrm{P}}=$ net energy value of product

$\mathrm{NHV}_{\mathrm{F}}=$ net energy value of feedstock

$\mathrm{PE}=$ process energy requirement

\section{REFERENCES}

Allen, D. T. Pollution Prevention: Engineering Design at Macro-, Meso, and Microscales. In: Wei, J., ed. Advances in Chemical Engineering, Vol. 19. Academic Press, New York (1994).

Azapagic, A. Life Cycle Assessment and its Application to Process Selection, Design and Optimization. Chemical Engineering Journal 73: 1 - 21 (1999).

General Motors Corporation, Argonne National Laboratory, BP, ExxonMobil and Shell. Well-to-Tank Energy Use and Greenhouse Gas Emissions of Advanced Fuel/Vehicle Systems: North American Analysis. Final Report, Argonne National Laboratory, U.S.A (2001).

Hauschild, M. and Wenzel, H. Environmental Assessment of Products. Vol. 2: Scientific Background. Chapman \& Hall, London (1997).
Hocking, M. B. Net Energy Expenditure: A Method for Assessing the Environmental Impact of Technologies. In: Schulze, P. C., ed. Measures of Environmental Performance and Ecosystem Condition. National Academy Press, Washington, D.C. (1999).

ISO 14040. Environmental Management - Life Cycle Assessment - Principles and Framework. International Organization for Standardization, Geneva (1997).

ISO 14041. Environmental Management - Life Cycle Assessment - Goal and Scope Definition and Inventory Analysis. International Organization for Standardization, Geneva (1998).

ISO 14042. Environmental Management - Life Cycle Assessment - Life Cycle Impact Assessment International Organization for Standardization, Geneva (2000a).

ISO 14043. Environmental Management - Life Cycle Assessment - Life Cycle Interpretation. International Organization for Standardization, Geneva (2000b).

Kaarstad, O. Fossil Fuels and Responses to Global Warming. Energy Conversion and Management 36: 869 - 872 (1995).

Lovins, A. B. Disruptive Transportation Technologies, Uncompromised Vehicles, and the Rapid Transition to Hydrogen. Industry and Environment 23: $10-13$ (2000).

Nieuwlaar, E., Alsena, E. and van Engelenburg, B. Using Life Cycle Assessment for the Environmental Evaluation of Greenhouse Gas Mitigation Options. Energy Conversion and Management 37: 831 836 (1996).

Panik, F. Joining Forces to Achieve Sustainable Mobility. Industry and Environment 23: $14-17$ (2000).

Philippine Department of Energy. Philippine Energy Plan 2000 - 2009. Manila (2000).

Sharatt, P. Environmental Criteria in Design. Computers \& Chemical Engineering 23: 1469 - 1475 (1997).

Sharke, P. Fueling the Cells. Mechanical Engineering 121: 46 - 49 (1999).

Tan, R. R. and Culaba, A. B. Life Cycle Inventory Assessment of Selected Energy Vectors for 
Philippine Automotive Transport. Proceedings of the $49^{\text {th }}$ National Convention of the Philippine Society of Mechanical Engineers, Manila (2001).

Wang, M. GREET 1.5 - Transportation Fuel Cycle Model. Final Report ANL/ESD-39, Argonne National Laboratory, U.S.A (1999).

Wenzel, H., Hauschild, M. and Alting, L. Environmental Assessment of Products. Vol. 1: Methodology, Tools and Case Studies in Product Development. Chapman \& Hall, London (1997).

World Resources Institute. World Resources 2000

- 2001. People and Ecosystems: The Fraying Web of Life. Washington, D.C. (2000).

\section{ABOUT THE AUTHORS}

Raymond R. Tan is an Assistant Professor of the Chemical Engineering Department of De La Salle University - Manila. He holds B.S. and M.S. degrees in Chemical Engineering from DLSU Manila, and is a candidate for a Ph.D. in Mechanical Engineering. His current research interests include Environmental Systems Modeling, Life Cycle Assessment (LCA), and Environmental Decision Support Systems.

Alvin B. Culaba is an Associate Professor of the Mechanical Engineering of Department De La Salle University - Manila. He has over fifteen years of experience in teaching, research, and consultancy. His research interests include Life Cycle Assessment (LCA), Environmental Impact Analysis of Manufacturing Processes, KnowledgeBased Systems Applications, Environmental Management Systems (EMS), Cleaner Production Technology, and Renewable Energy Systems. He holds a Ph.D. in Mechanical/Environmental Engineering from the University of Portsmouth in the United Kingdom. 